\title{
PENURUNAN KADAR ZAT WARNA RODAMIN B MENGGUNAKAN HUMIN HASIL ISOLASI DARI TANAH HUTAN DAMAR BATURRADEN
}

\author{
Tien Setyaningtyas dan Roy Andreas \\ Program Studi Kimia, Jurusan MIPA, Fakultas Sains dan Teknik, UNSOED, Purwokerto
}

\begin{abstract}
Humin was isolated from the Baturraden resin forest and purified use mixture of $\mathrm{HCl}$ :HF. Purified humin is characterised such as identify of functional group of humin, stipulating of water content, stipulating of dust content, obstetrical stipulating of total acidity content, carboxylic and $\mathrm{OH}$ phenolic functional group. The adsorption of rodamin by humin measured by UV-Visible spectrophotometer at maximum wavelength of rodamin $\mathrm{B}$ liquid, optimum $\mathrm{pH}$ and optimum contact time to determine absorbtion capacities and isotherm adsorption pattern .Humin that isolated from Baturraden resin forest have characteristic such as water content $16.6199 \%$; dust content $9.2050 \%$; total acidity content $475 \mathrm{cmol} / \mathrm{Kg}$; carboxylic rate $200 \mathrm{cmol} / \mathrm{Kg}$, and $\mathrm{OH}$ phenolic rate $275 \mathrm{cmol} / \mathrm{Kg}$. Maximum wavelength of rodamin B is $554 \mathrm{~nm}$ and optimum contact time of adsorption rodamin $\mathrm{B}$ by humin is 180 minute with optimum $\mathrm{pH} 4$. Adsorption rodamin $\mathrm{B}$ by humin follows the pattern of Langmuir isotherm adsorption with the value of $\mathrm{R}^{2}$ is 0.9801 and absorption capacities is $39,5257 \mathrm{mg} / \mathrm{g}$.
\end{abstract}

Key words : Rodamin B, Humin, isolation

\section{PENDAHULUAN}

Perkembangan industri yang semakin pesat menuntut produsen untuk meningkatkan nilai produknya. Peningkatan nilai produk dapat dilakukan dengan penambahan zat warna. Zat warna banyak digunakan pada industri makanan, tekstil, obat-obatan dan kosmetik. Terlepas dari manfaatnya untuk meningkatkan nilai produk, ternyata penggunaan zat warna dapat mencemari lingkungan apabila dibuang ke lingkungan tanpa pengolahan terlebih dahulu (Suwarsa, 1998).

Salah satu zat warna yang banyak digunakan pada industri tekstil adalah Rodamin B. Rodamin B selain sebagai pewarna tekstil, juga banyak digunakan pada industri kosmetik dan makanan. Rodamin B merupakan pewarna merah berbahaya yang dapat larut dalam air, metanol dan etanol. Rodamin B bersifat karsinogen dan dapat mencemari lingkungan apabila pembuangan limbahnya tanpa melalui pengolahan (Manurung, dkk., 2004).

Beberapa metode sudah dikembangkan untuk mengatasi masalah limbah cair zat warna, antara lain metode adsorpsi. Adsorpsi merupakan suatu teknik yang efisien untuk menghadapi masalah kontaminasi limbah cair domestik dan industri karena dapat menghilangkan bau serta menurunkan kadar zat warna dari larutan dengan sempurna tanpa mengubahnya menjadi senyawa yang lebih berbahaya. Metode adsorpsi untuk menurunkan kadar zat warna telah banyak dilakukan dengan berbagai material adsorben. Salah satu adsorben yang potensial untuk menurunkan zat warna adalah humin yang terkandung di dalam tanah.

Tanah tersusun dari komponen organik dan anorganik. Komponen organik tanah terbagi dalam dua kelompok yaitu bahan humat dan non humat. Bahan non humat meliputi 
karbohidrat, asam amino, protein, lipid asam nukleat dan lignin. Bahan humat merupakan hasil akhir dekomposisi bahan tanaman di dalam tanah (Tan, 1982). Bahan humat bersifat reaktif karena mempunyai elektronegativitas yang besar. Gugus $-\mathrm{COOH},-\mathrm{OH}$ fenolat, $-\mathrm{OH}$ alkoholat serta $-\mathrm{C}=\mathrm{O}$ pada bahan humat mempunyai kemampuan untuk mengadsorpsi limbah cair zat warna. Berdasarkan karakteristik kelarutannya, bahan humat digolongkan dalam tiga fraksi yaitu asam humat, asam fulvat dan humin. Humin merupakan fraksi yang tidak dapat larut dalam alkali, asam atau alkohol. Martin dan Saab (2004) menyatakan bahwa humin merupakan fraksi terbesar bahan humat. Sebagai fraksi bahan humat, humin memiliki gugus karboksilat dan gugus $-\mathrm{OH}$ fenolat yang dapat mengadsorpsi limbah cair zat warna, namun masih sedikit penelitian tentang humin dan pemanfaatan humin sebagai material adsorben limbah cair zat warna. Berdasarkan pernyataan di atas maka dalam penelitian ini dilakukan karakterisasi humin dari tanah hutan damar Baturraden dan kemampuan adsorpsi humin terhadap zat warna Rodamin serta pola isoterm adsorpsinya.

\section{METODE PENELITIAN}

\section{Isolasi dan Pemurnian Humin}

Humin diisolasi dari tanah hutan damar Baturraden. Sampel tanah dibersihkan dari kerikil dan pengotor dengan cara diayak. Sebanyak $2 \mathrm{~g}$ sampel tanah yang telah dibersihkan diekstraksi dengan $100 \mathrm{~mL}$ larutan $\mathrm{NaOH}$ 0,5 $\mathrm{M}$ dengan media botol plastik ukuran 1,5 L kemudian ditambahkan gas nitrogen $\left(\mathrm{N}_{2}\right)$, ditutup rapat dan dikocok dengan bantuan shaker selama 24 jam. Residu ekstraksi dipisahkan dari larutan dengan sentrifugasi pada kecepatan 2500 rpm selama 15 menit, lalu didekantasi. Selanjutnya, dilakukan pengasaman dengan menambahkan $\mathrm{HCl} 6 \mathrm{M}$ hingga $\mathrm{pH}<2$. Residu disaring dengan buchner,

dibilas dengan larutan $\mathrm{HCl}$ 0,01 $\mathrm{M}$ dan dibebasionkan dengan akuades kemudian dikeringkan dengan udara. Humin yang diperoleh dari tahap ini merupakan humin kotor.

Ekstraksi humin dilanjutkan dengan tahap pemurnian. Humin kotor diekstraksi dengan larutan campuran HF$\mathrm{HCl}$ sebanyak tiga tahap. Tahap pertama, humin kotor dicampur dengan $(1: 1 \mathrm{v} / \mathrm{v})$ 0,2 $\mathrm{M} \mathrm{HCl}$ dan 0,2 M HF selama 64 jam lalu disaring. Tahap kedua, residu yang diperoleh dimasukkan dalam campuran 1:1 $\mathrm{HF}(5,5)$ dan $\mathrm{HCl}(1,1 \mathrm{M})$ tiga kali selama satu jam, masing-masing didekantasi. Tahap ketiga, residu dimasukkan dalam larutan 5,5 M HF empat kali masing-masing selama 16 jam. Endapan dipisahkan dari pelarutnya dengan sentrifugasi pada kecepatan 2500 rpm selama 15 menit, didekantasi, dibilas dengan $0,1 \mathrm{M} \mathrm{HCl}$ dan terakhir dibilas dengan akudes empat kali. Residu yang diperoleh merupakan humin yang bebas pengotor. Selanjutnya humin dikeringkan dengan udara, dihaluskan, diayak dengan ayakan 120 mesh lalu disimpan dalam desikator.

\section{Karakterisasi Humin (SNI, 2002) Identifikasi gugus fungsional humin}

Humin kotor dan humin yang telah dimurnikan dikarakterisasi menggunakan metode spektroskopi inframerah (FTIR) untuk mengetahui gugus fungsinya.

\section{Penetapan kadar air}

Sebanyak $50 \mathrm{mg}$ humin hasil
isolasi yang telah dikeringkan
dimasukkan ke dalam cawan porselin
yang telah diketahui bobotnya. Cawan
berisi humin tersebut dipanaskan dalam
oven pada suhu $105^{\circ} \mathrm{C}$ selama 24 jam dan
didinginkan dalam desikator kemudian
ditimbang. Masing-masing dilakukan dua
kali (duplo).




\section{Penetapan kadar abu}

Penetapan kadar abu dilakukan dengan pembakaran dalam tungku perapian (furnace) pada temperatur $440^{\circ} \mathrm{C}$ selama 6 jam, setelah dilakukan pengujian kadar air. Masing-masing dilakukan dua kali (duplo).

\section{Penetapan keasaman total (KT)}

Sebanyak $20 \quad \mathrm{mg}$ humin dimasukkan ke dalam erlenmeyer 125 $\mathrm{mL}$ dan ditambahkan $10 \mathrm{~mL}$ larutan $\mathrm{Ba}(\mathrm{OH})_{2}$ 0,2 $\mathrm{N}$ dalam kondisi atmosfer nitrogen. Erlenmeyer ditutup rapat dan dishaker selama 24 jam pada temperatur kamar. Suspensi yang terbentuk disaring kemudian residu dibilas dengan aquades bebas $\mathrm{CO}_{2}$, filtrat dan air bilasan digabung lalu dititrasi secara potensiometri dengan larutan standar $\mathrm{HCl}$ $0,2 \mathrm{~N}$ hingga $\mathrm{pH} \mathrm{8,4}$. Titrasi ini juga dilakukan pula terhadap larutan blangko yaitu larutan jenuh $\mathrm{Ba}(\mathrm{OH})_{2} \quad 0,2 \mathrm{~N}$ sebanyak $10 \mathrm{~mL}$. Perhitungan keasaman total dilakukan dengan rumusan sebagai berikut,

$K T=\frac{(V b-V s) \times N x 10^{5}}{\text { miligram sampel }} \mathrm{cmol} / \mathrm{kg}$

Keterangan :

$\mathrm{Vb}=$ volume $\mathrm{HCl}$ yang digunakan untuk mentitrasi blangko, Vs $=$ volume $\mathrm{HCl}$ yang digunakan untuk mentitrasi sampel $\mathrm{N}=$ normalitas larutan standar asam

\section{Penetapan kandungan gugus karboksilat}

Sebanyak $20 \quad \mathrm{mg}$ humin dimasukkan ke dalam erlenmeyer dan ditambahkan $10 \mathrm{~mL}$ larutan $\mathrm{Ba}\left(\mathrm{CH}_{3} \mathrm{COO}\right)_{2}$ 0,2 $\mathrm{M}$ dan $40 \mathrm{~mL}$ aquades bebas $\mathrm{CO}_{2}$. Dalam waktu yang sama juga dilakukan pula terhadap larutan blangko yaitu $10 \mathrm{~mL}$ larutan $\mathrm{Ba}\left(\mathrm{CH}_{3} \mathrm{COO}\right)_{2} \quad 0,2$ $\mathrm{M}$ dan $40 \mathrm{~mL}$ aquades bebas $\mathrm{CO}_{2}$ kemudian larutan dishaker selama 24 jam pada suhu kamar. Suspensi yang terbentuk disaring kemudian residu dibilas dengan air destilat bebas $\mathrm{CO}_{2}$. Filtrat dan air bilasan digabung, kemudian dititrasi dengan menggunakan larutan standar $0,1 \mathrm{M} \mathrm{NaOH}$ hingga $\mathrm{pH}$ 9,8 . Perhitungan kandungan gugus karboksilat dilakukan dengan rumusan sebagai berikut,

$$
[-\mathrm{COOH}]=\frac{(\mathrm{Vs}-\mathrm{Vb}) \times \mathrm{N} \times 10^{5}}{\text { miligram sampel }} \mathrm{cmol} / \mathrm{kg}
$$

Keterangan : $\mathrm{Vb}=$ volume $\mathrm{NaOH}$ yang digunakan untuk mentitrasi blangko, Vs $=$ volume $\mathrm{NaOH}$ yang digunakan untuk mentitrasi sampel, $\mathrm{N}=$ normalitas larutan standar basa

\section{Penetapan kandungan gugus $\mathrm{OH}$ fenolat}

Kandungan gugus $-\mathrm{OH}$ fenolat merupakan selisih antara kemasaman total dengan kandungan gugus $-\mathrm{COOH}$. Perhitungan kandungan gugus $\mathrm{OH}$ fenolat dalam $\mathrm{cmol} / \mathrm{kg}$ dilakukan dengan rumusan sebagai berikut,

$[\mathrm{OH}]$ fenol $=$ keasaman total $-[\mathrm{COOH}]$

\section{Penentuan panjang gelombang maksimum}

Larutan baku zat warna rodamin B $1000 \mathrm{mg} / \mathrm{L}$ disiapkan dengan melarutkan $0,5 \mathrm{~g}$ zat warna rodamin B pada $500 \mathrm{~mL}$ akuades. Larutan eksperimen disiapkan dari $2 \mathrm{~mL}$ larutan baku yang diencerkan hingga $100 \mathrm{~mL}$ dengan akuades untuk mendapatkan larutan dengan konsentrasi $20 \mathrm{mg} / \mathrm{L}$. Pengukuran panjang gelombang maksimum dilakukan pada panjang gelombang 550-560 nm dengan spektrofotometer UV-Vis.

\section{Penentuan waktu kontak optimum dengan variasi $\mathbf{p H}$}

Sebanyak 0,05 g humin dalam 25 $\mathrm{mL}$ larutan rodamin B $20 \mathrm{mg} / \mathrm{L}$, diatur pada $\mathrm{pH} 2,3,4,5,6,7,8,9$ dan 10 dengan penambahan buffer, kemudian dikocok dengan variasi waktu kontak 2 , $10,20,40,60,90,120,150,180,210$ dan 240 menit. Larutan kemudian disaring, filtrat yang dihasilkan diukur absorbansinya pada panjang gelombang maksimum dengan spektrofotometer UV- 
Vis. Banyaknya rodamin B yang terserap merupakan selisih konsentrasi awal dan akhir rodamin $B$.

\section{Penentuan kapasitas penyerapan} rodamin $B$ dan pola isoterm adsorpsi

Sebanyak 0,05 g humin ditambah pada $25 \mathrm{~mL}$ larutan rodamin B dengan variasi konsentrasi rodamin B 5, 10, 20, 40, 60, 80 dan $100 \mathrm{mg} / \mathrm{L}$, dikocok pada waktu kontak dan $\mathrm{pH}$ optimum. Larutan kemudian disaring dengan kertas saring whatman nomor 41, filtrat yang dihasilkan diukur absorbansinya pada panjang gelombang maksimum dengan spektrofotometer UV-Vis, filtrat kemudian diukur kapasitas penyerapannya.

\section{HASIL DAN PEMBAHASAN Karakteristik Humin}

Hasil analisis kualitatif gugus fungsional humin sebelum dan setelah proses pemurnian dapat dilihat pada Gambar 1 dan 2.

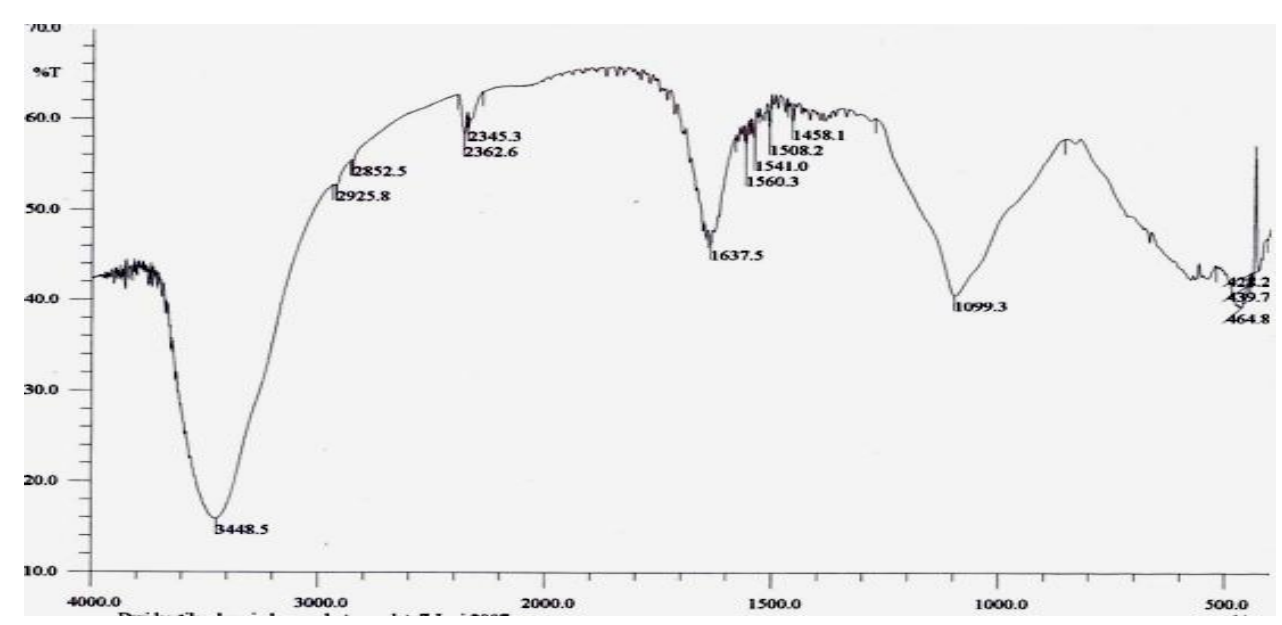

Gambar 1. Spektrum IR humin hasil isolasi sebelum pemurnian

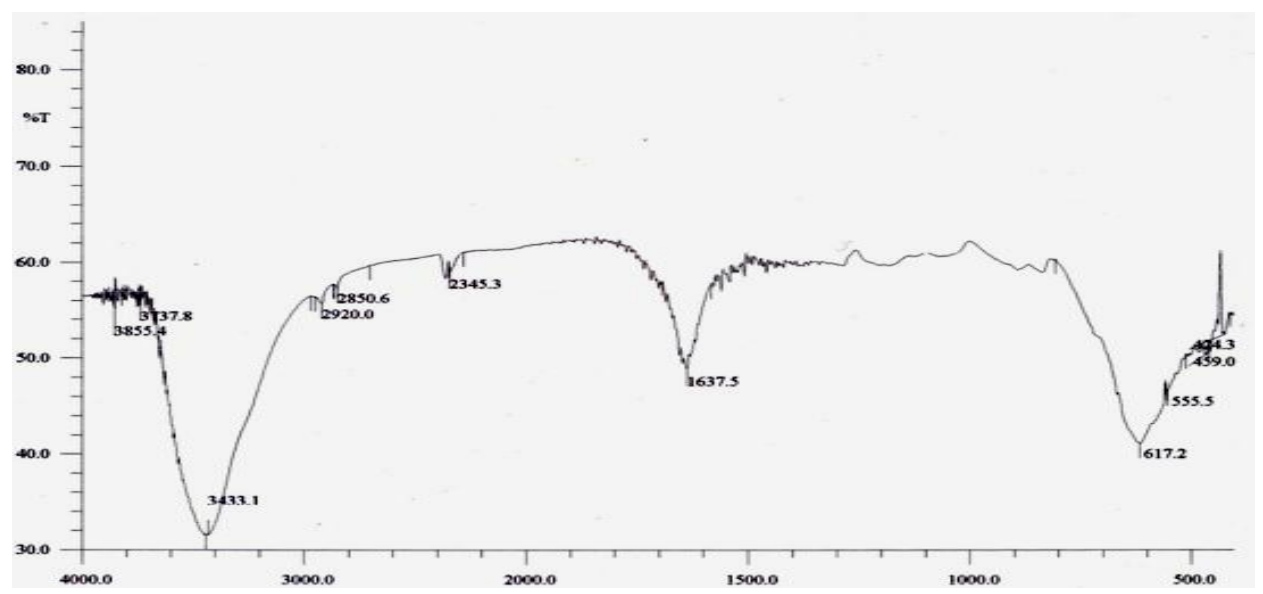

Gambar 2. Spektrum IR humin hasil isolasi setelah pemurnian

Spektrum IR humin sebelum pemurnian dan setelah pemurnian menunjukkan adanya persamaan dan perbedaan pada pita serapannya. Gugus $\mathrm{OH}$ terlihat pada pita serapan dengan bilangan gelombang 3433,1 $\mathrm{cm}^{-1}$. 
Bilangan gelombang 1637,5 $\mathrm{cm}^{-1}$ menunjukkan vibrasi ulur $\mathrm{C}=\mathrm{C}$ aromatik atau $\mathrm{C}=\mathrm{O}$ (keton terkonjugasi) mengikat hidrogen, sedangkan bilangan gelombang $2920 \mathrm{~cm}^{-1}$ dan 2850,6 $\mathrm{cm}^{-1}$ merupakan vibrasi ulur $\mathrm{C}-\mathrm{H}$ alifatik. Adanya $-\mathrm{OH}$ dari $-\mathrm{COOH}$ ditunjukkan dengan pita serapan pada bilangan gelombang 2345,3 $\mathrm{cm}^{-1}$ (Creswell, 1982).

Perbedaan spektrum pada humin kotor dan humin murni yaitu hilangnya pita serapan pada bilangan gelombang di sekitar $1500 \mathrm{~cm}^{-1}-1400 \mathrm{~cm}^{-1}$ dan bilangan gelombang $1099,3 \mathrm{~cm}^{-1}$ pada humin bersih. Menurut Noerdin (1985) pita serapan yang kuat di daerah 1090 $\mathrm{cm}^{-1}$ menunjukkan adanya ikatan $\mathrm{S}=\mathrm{O}$ sehingga pada humin murni pita serapan pada daerah ini tidak muncul. Pita serapan pada bilangan gelombang 1430 $\mathrm{cm}^{-1}-1630 \mathrm{~cm}^{-1}$ biasanya ditimbulkan oleh cincin benzena tersubtitusi. Bilangan gelombang $1540,1 \mathrm{~cm}^{-1}$ merupakan vibrasi ulur deformasi $\mathrm{NH}_{2}$ dan pita serapan pada bilangan gelombang 1458,1 $\mathrm{cm}^{-1}$ merupakan gugus etoksi pada atom fosfor. Munculnya pita serapan pada bilangan gelombang 617,2 $\mathrm{cm}^{-1}$ mengidentifikasikan adanya gugus $\mathrm{SiCl}_{3}$. Noerdin (1985) menyatakan bahwa gugus $\mathrm{SiCl}_{3}$ menyerap dengan kuat pada bilangan gelombang $620 \mathrm{~cm}^{-1}-570 \mathrm{~cm}^{-1}$ dan gugus $\mathrm{SiCl}_{3}$ menyerap pada bilangan gelombang $625 \mathrm{~cm}^{-1}-420 \mathrm{~cm}^{-1}$.

Kadar air merupakan banyaknya air yang terkandung dalam bahan yang dinyatakan dalam persen (Stevenson, 1994).

Tabel 1. Kadar air humin hasil isolasi

No. Humin Kadar air (\%)

\begin{tabular}{lll}
\hline 1. & Kotor & 18,8675 \\
2. & Murni & 16,6199 \\
\hline
\end{tabular}

Kadar abu suatu bahan adalah kadar residu hasil pembakaran semua komponen organik di dalam bahan yang biasanya berupa mineral.

Tabel 2. Kadar abu humin hasil isolasi

\begin{tabular}{ccc}
\hline No. & Humin & Kadar abu (\%) \\
\hline 1. & Kotor & 67,1975 \\
2. & Murni & 9,2050 \\
\hline
\end{tabular}

Penentuan gugus fungsional humin secara kuantitatif yaitu nilai keasaman total, gugus karboksilat dan gugus $-\mathrm{OH}$ fenolat dilakukan dengan metode titrasi potensiometri.

Tabel 3. Kandungan gugus fungsional humin hasil isolasi

\begin{tabular}{clc}
\hline No. & \multicolumn{1}{c}{$\begin{array}{c}\text { Gugus } \\
\text { fungsional }\end{array}$} & $\begin{array}{c}\text { Kandungan } \\
(\mathrm{cmol} / \mathrm{kg})\end{array}$ \\
\hline 1. & Keasaman total & 475 \\
2. & Karboksilat & 200 \\
3. & OH fenolat & 275 \\
\hline
\end{tabular}

\section{Penggunaan Humin untuk Menurunkan Zat Warna Rodamin B.}

\section{Penentuan panjang gelombang maksimum rodamin $B$}

Panjang gelombang maksimum larutan rodamin B yang diperoleh adalah $554 \mathrm{~nm}$ dengan nilai absorbansi 0,556. Nilai panjang gelombang maksimum selanjutnya digunakan untuk mengukur absorbansi pada proses berikutnya. 


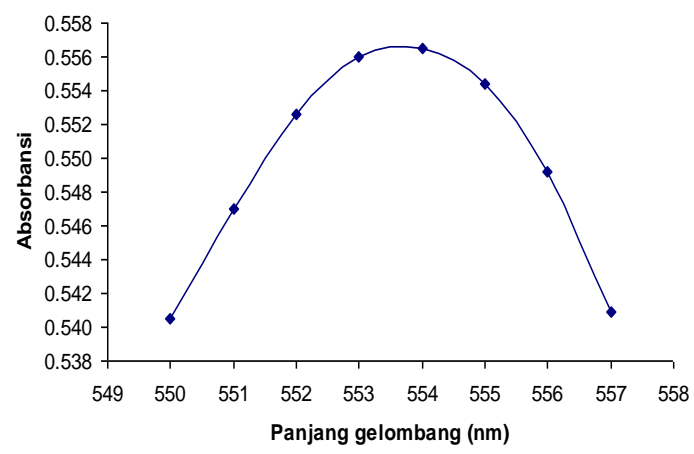

Gambar 3. Penentuan panjang gelombang maksimum Rodamin B

\section{Penentuan waktu kontak optimum dengan variasi $\mathbf{p H}$}

Waktu kontak optimum merupakan waktu pengocokan humin dengan rodamin B dimana terjadi adsorpsi rodamin B yang paling besar oleh humin. Penentuan waktu kontak optimum dilakukan dengan variasi $\mathrm{pH}$ untuk menentukan nilai $\mathrm{pH}$ optimum. Waktu kontak optimum adsorpsi rodamin B oleh humin yang diperoleh yaitu 180 menit dengan nilai $\mathrm{pH}$ optimum 4.

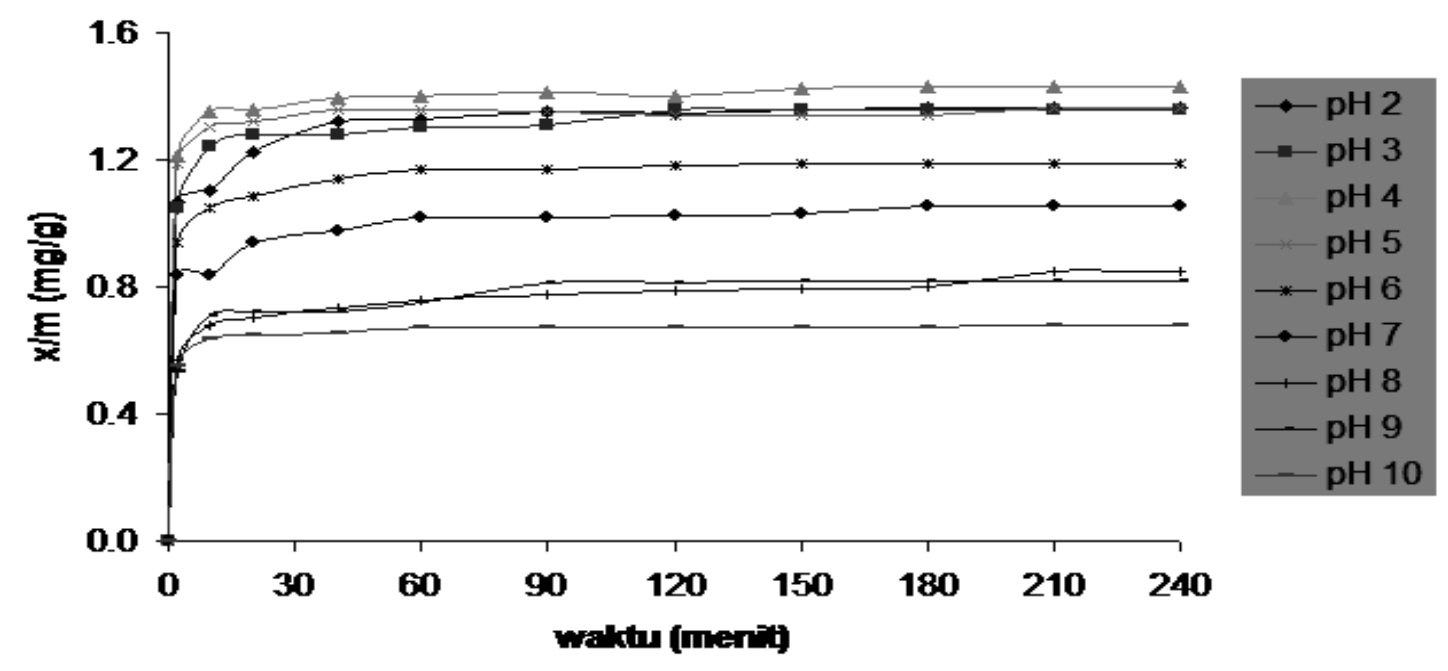

Gambar 4. Kurva waktu kontak optimum dengan variasi $\mathrm{pH}$

\section{Penentuan kapasitas penyerapan dan isoterm adsorpsi.}

Penentuan kapasitas penyerapan dilakukan dengan menginteraksikan humin dengan larutan rodamin B pada pH 4 dengan berbagai konsentrasi selama 180 menit. Kurva hubungan antara konsentrasi rodamin B $(\mathrm{mg} / \mathrm{L})$ dengan rodamin B yang terserap $(\mathrm{mg} / \mathrm{g})$ dapat dilihat pada Gambar 5.

Pola isoterm adsorpsi ditentukan dua persamaan yaitu isoterm adsorpsi

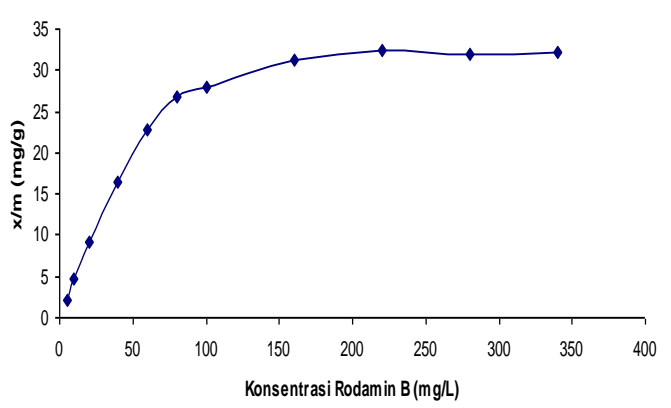

Gambar 5. Kurva hubungan antara konsentrasi rodamin B (mg/L) dengan Rodamin B yang terserap $(\mathrm{mg} / \mathrm{g})$

langmuir dan Freundlich. Isoterm adsorpsi menggambarkan suatu keadaan 
kesetimbangan pada proses adsorpsi (Arivoli dan Thenkuzhali, 2008) Penentuan jenis isoterm adsorpsi dilakukan dengan membandingkan $\mathrm{R}^{2}$ pada isoterm Langmuir dan Freundlich seperti terlihat pada Tabel 6 .

Tabel 6. Perbandingan pola isoterm adsorpsi langmuir dan freundlich

\begin{tabular}{|c|c|c|}
\hline Isotherm & Persamaan & $\mathrm{R}^{2}$ \\
\hline Langmuir & $\begin{array}{l}y=0,0253 x+ \\
1,4688\end{array}$ & 0,9801 \\
\hline Freundlich & $\begin{array}{l}y=0,6286 x+ \\
0,0894\end{array}$ & 0,9027 \\
\hline
\end{tabular}
adalah,

$$
\text { Persamaan isoterm Langmuir }
$$$$
\frac{C}{m}=\frac{1}{b \cdot K}+\frac{C}{b}
$$

Dimana $m$ adalah jumlah adsorbat teradsorpsi per gram adsorben pada konsentrasi $\mathrm{C}, \mathrm{K}$ adalah konstanta kesetimbangan (afinitas adsorpsi), C adalah konsentrasi ion logam saat kesetimbangan dan $\mathrm{b}$ adalah adsorbat yang teradsorpsi pada keadaan jenuh (kapasitas adsorpsi maksimum).

Persamaan isoterm Langmuir yang diperoleh adalah $\mathrm{y}=0,0253 \mathrm{x}+$ 1,4688 dengan nilai $\mathrm{R}^{2}$ sebesar 0,9801 . Nilai kapasitas adsorpsi maksimum ditentukan dengan menentukan nilai $b$ pada persamaan isoterm Langmuir diatas dan diperoleh $39,5257 \mathrm{mg} / \mathrm{g}$.

\section{DAFTAR PUSTAKA}

Arivoli, S dan M. Thenkuzhali. 2008. Kinetic, Mechanistic, Thermodynamic and Equilibrium Studies on the Adsorption of Rhodamine B by Acid Activated Low Cost Carbon. E-Journal of Chemistry. Vol 5 (2): 87-200.
Persamaan isoterm Freundlich adalah, $\log m=1 / n \log C+\log K$

Dimana nilai log $\mathrm{m}$ diplot sebagai sumbu $\mathrm{y}$ dan $\log \mathrm{C}$ sebagai sumbu $\mathrm{x}$ maka diperoleh persamaan isoterm Freundlich yaitu $\mathrm{y}=0,6286 \mathrm{x}+0,0894$ dengan nilai $\mathrm{R}^{2}$ sebesar 0,9027.

Tabel 6 menunjukkan bahwa nilai $\mathrm{R}^{2}$ pada kurva isoterm adsorpsi Langmuir lebih besar dibandingkan dengan nilai $\mathrm{R}^{2}$ pada kurva isoterm adsorpsi Freundlich, sehingga diketahui bahwa adsorpsi rodamin B oleh humin mengikuti persamaan isoterm adsorpsi Langmuir.

\section{KESIMPULAN}

1. Karakteristik humin hasil isolasi dari tanah hutan damar Baturraden memiliki kadar air 16,6199\%; kadar abu 9,2050\%; kandungan keasaman total $475 \mathrm{cmol} / \mathrm{kg}$; kandungan gugus karboksilat $200 \quad \mathrm{cmol} / \mathrm{kg}$ dan kandungan gugus $-\mathrm{OH}$ fenolat 275 $\mathrm{cmol} / \mathrm{kg}$.

2. Adsorpsi Rodamin B oleh humin hasil isolasi tanah hutan damar Baturraden mempunyai waktu kontak setimbang 180 menit dengan $\mathrm{pH}$ optimum 4.

3. Isoterm adsorpsi Rodamin B oleh humin hasil isolasi dari tanah hutan damar Baturraden mengikuti persamaan isoterm adsorpsi Langmuir dengan kapasitas penyerapan 39,5257 $\mathrm{mg} / \mathrm{g}$.

Creswell, J.C., A. Runquist dan M.M. Campbell. 1982. Analisis Spektrum Senyawa Organik. Penerbit ITB. Bandung.

Manurung, R., R. Hasibuan dan Irvan. 2004. Perombakan Zat Warna Azo Reaktif Secara AnaerobAerob. Jurusan Teknik Kimia Universitas Sumatera Utara. 
Martin, N dan S.C. Saab. 2004. Studies of Semiquinone Free Radicals by ESR in the Whole Soil, HA, FA and Humin Substances. J. Braz. Chem. Soc., Vol. 15 (1) : 34-37.

Noerdin, D. 1985. Elusidasi Struktur Senyawa Organik Dengan Cara Spektroskopi Ultra Lembayung Dan Inframerah. Angkasa. Bandung.

SNI. 2002. Metode Pengujian Kadar Air, Kadar Abu dan Bahan Organik dari Tanah Gambut dan Tanah
Organik Lainnya. SNI 13-67932002

Stevenson, F.J. 1994. Humus Chemistry, Genesis, Composition, Reaction. J.Whiley. New York.

Suwarsa, S. 1998. Penyerapan Zat Warna Tekstil BR Red HE 7B Oleh Jerami Padi. JMS Vol 3 (1):32 40

Tan, K. H. 1982. Priciples of Soil Chemistry. Marcel Dekker. New York. 